\title{
Observatorio de Tendencias
}

Marina Perez Zelaschi *

\begin{abstract}
Resumen: Observatorio de tendencias del INTI Textiles: su razón de ser, el contexto social y productivo, las formas de trabajo del grupo multidisciplinario, los aportes metodológicos, los resultados de más de una década de interpretación de los fenómenos del vestir, tanto nacionales como internacionales, haciendo accesible la información a diseñadores, emprendedores y empresarios de todo el país.
\end{abstract}

Palabras clave: difusión - diseño de autor observación - tendencias en indumentaria.

[Resúmenes en inglés y portugués en la página 42]

(*) Ingeniera Industrial y Química (ITBA), con Maestría en Marketing (ESEM-España). Es docente de Posgrado en Comercialización Estratégica en la UTN, Facilitadora de procesos grupales y de aprendizaje para adultos (CEFE y GTZ) y Tutora de jóvenes emprendedores (ACDE).

\section{Creando contexto}

El Observatorio de tendencias del INTI Textiles, que fue concebido a fines de los '90, ha ido evolucionado de manera sincrónica con la evolución de las empresas y el contexto internacional del fenómeno de la moda, etimológicamente "lo que se ve " de la moda, esencialmente empírico y sensible.

El INTI -Instituto Nacional de Tecnología Industrial- como organismo público al servicio de los consumidores, de las empresas y las entidades del sector, acompaña con anticipación el desarrollo productivo de toda la cadena de valor textil-indumentaria.

Las decisiones estratégicas tomadas por el final del milenio pasado en el Centro de Investigación y Desarrollo Textil - INTI textiles, avizoraban un pujante potencial de creatividad plasmada en diseño en series cortas, con una marcada identidad propia, como conjunción de una serie de factores casi contemporáneos: por un lado, la profesionalización del diseño de indumentaria, con crecimiento explosivo en la matricula de las Universidades, tanto públicas como privadas; por otro lado, la desestructuración de las empresas textiles integradas, aunado a la tercerización de la fabricación de prendas en unidades productivas de tamaño mucho menor. Ambas circunstancias alentaban la posibilidad de empresas con una gestión de diseño profesionalizada, de menor tamaño, con capacidad de insertarse exitosamente en el mercado, tanto 
nacional como internacional. Por otra parte, aún en contextos económicamente desfavorables, las empresas de indumentaria con marcas locales habían sido capaces de sostener estrategias de abastecimiento del mercado nacional.

El desarrollo del Observatorio a fines de los '90 tenía su eje en la recolección de información sobre moda y tendencias en los centros internacionales de la moda (París y Milán), habida cuenta de las dificultades en su obtención, tanto por los costos de adquisición como por las dificultades intrínsecas a un mercado poco profesionalizado, altamente intuitivo.

De allí, que el primer nombre del servicio fuera "Infomoda"(1999) recogiendo las dos características primarias del servicio: la recolección de información y su contenido. La finalidad era que las empresas, en particular las de menor dimensión económica y los nuevos emprendedores del sector tuvieran información de primera mano, elaborada por profesionales del diseño, con formación de posgrado en instituciones líderes europeas, fundamentalmente italianas, accesible en cuanto a costos y posibilidades de interpretación.

El eje de la accesibilidad sigue siendo una premisa rectora para el actual Observatorio de Tendencias, que centra su servicio en la interpretación de los fenómenos del vestir, no sólo en los centros tradicionales sino en los emergentes latinos y nuestro propio país. Esto se debe a que, en el marco de la democratización en el acceso a la información, el complemento de la interpretación cobra aún más valor estratégico.

\section{Ejes estratégicos del Observatorio}

Algunas reflexiones que hacen al corazón y la cabeza de lo que es el Observatorio de Tendencias del INTI textiles:

La primera reflexión es que se ha elegido a la observación directa del fenómeno del vestir como método de relevamiento. Existen dos razones básicas: la primera se basa en las premisas enunciadas tan claramente por el sociólogo chileno Rafael Echeverría (2005): "No sabemos como las cosas son. Sólo sabemos como las observamos o como las interpretamos. Vivimos en mundos interpretativos". O, dicho de otra manera, al estilo de Joan Manuel Serrat, en el metro, "el escritor ve lectores... los banqueros ven morosos... el casero ve inquilinos, el general ve soldados... juanetes, el pedicuro... la comadrona pasado y el enterrador, futuro...”

La segunda razón se basa, valga el oximoron, en la irracionalidad que acompaña toda decisión de compra y que se traslada a la decisión del atuendo que elegimos para cada momento del día. Los estudios más recientes de marketing, utilizando las técnicas de escaneo cerebral por resonancia magnética, dan cuenta de que tomamos todo tipo de decisiones de compra, en no más de 3 segundos y concluyen que las emociones determinan el rumbo de las decisiones, mucho más decididamente que la razón o el pensamiento crítico.

Esta perspectiva presenta un abierto desafío a la lógica tradicional de la investigación de mercado cuali-cuantitativa, en la cual los sujetos objeto de la investigación, se ven "obligados" por las circunstancias de darle racionalidad a eventos que mayoritariamente están regidos por procesos irracionales e instantáneos.

De allí la elección de un método como la observación, para mirar con atención y examinar detenidamente el fenómeno de la moda, utilizando en esta mirada al sujeto observador entre- 
nado, como intérprete de la realidad.

La segunda reflexión es la necesidad humana de anticipación sobre el futuro, un intento de construcción de un futuro deseado desde nuestro hoy, una manera de reducir la incertidumbre en la que nos envuelve lo que vendrá. Como decía Woody Allen (2003) "me interesa el futuro porque es allí donde voy a pasar el resto de mi vida” y esta mirada interpretativa y de proyección a futuro es la que lidera el accionar del Observatorio, tanto para futuros definidos como cercanos -las dos próximas temporadas- o más lejanos, en la interpretación de tendencias sociales y de consumo global, de 3 a 5 años.

La tercera reflexión se basa en la construcción de interpretaciones compartidas por un equipo de profesionales, observadores entrenados pero individuales, provenientes de diferentes disciplinas. Con este equipo se consigue desterrar "una idea fija, que siempre parece una gran idea, no porque sea grande sino porque ocupa todo nuestro cerebro" como decía Jacinto Benavente (www.citasyproverbios.com).

En síntesis, la observación, apoyada en la intuición creativa, la interpretación consensuada de varias miradas profesionales y la difusión accesible, constituyen los ejes estratégicos del Observatorio.

\section{La observación}

$\mathrm{Al}$ asumir que vivimos en mundos interpretativos, el punto de partida fundamental lo constituye el equipo de trabajo: multifacético, integrando diferentes disciplinas complementarias (diseñadores textiles, de indumentaria, especialistas en marketing, diseñadores gráficos, sociólogos, especialistas en ciencias sociales, ingenieros). A este equipo le aportan conocimientos y saberes técnicos los demás profesionales del INTI textiles que, a su vez tiene un nutrido plantel donde hay desde psicólogos e ingenieros hasta abogados. Otros factores importantes en la amplitud de las percepciones lo son la integración etaria del equipo, las diferentes trayectorias laborales y docentes de los integrantes del Observatorio y la actuación a tiempo parcial de profesionales externos, como consultores.

\section{El proceso de la investigación, con foco global}

\section{Investigación de fuentes secundarias}

El proceso se inicia con una fase de investigación de escritorio o de fuentes secundarias, clásica, basada esencialmente en búsquedas por Internet, en bibliografía de tendencias y diseño, publicaciones especializadas y periódicas de materiales textiles, de tendencias en consumo de todo tipo de bienes y servicios, material de difusión en ferias etc. También se incluyen, como fuentes, el material e imágenes, textos, en distintos medios masivos de comunicación, tanto del arte, la política, la cultura, la economía.

Esta primera fase tiene por finalidad la indagación flexible, el recorrido por las marginalidades, 
la búsqueda desestructurada. Se presentan momentos de profunda incertidumbre, sobre cómo relacionar los hechos, imágenes emergentes. El aprendizaje grupal alcanzado nos permite transitar esta fase que es incierta, donde prima el dejarse permear, darle cabida a ideas periféricas. Esta fase del proceso puede ser caótica por momentos, vertiginoso, decididamente no lineal.

\section{Investigación de campo, a nivel global}

De este relevamiento inicial se detectan aquellas ciudades llave que podrán proveer información clave para la interpretación de fenómenos emergentes, a las que se suman destinos tradicionales relacionados con la indumentaria, donde ocurren las principales ferias y exposiciones del sector. Una vez completada la fase de investigación de fuentes secundarias, se pasa al diseño del relevamiento in situ: esto significa que el equipo decide las Ferias de indumentaria y textiles que se visitarán y los centros urbanos tradicionalmente referentes del sector y los detectados como focales emergentes. La selección de eventos y destinos habitualmente incluye no menos de 5 ciudades, con sus circuitos asociados.

El equipo que realizará la investigación de campo, rota en forma continua y es frecuente que en cada temporada participen del relevamiento más de dos profesionales. En cada oportunidad se recorren los circuitos más emblemáticos en las ciudades tradicionales y se incorporan los nuevos barrios/zonas/calles de diseño.

Lo observado recorre las líneas de: aquello que resulta novedoso, no visto antes; lo que tiene sutiles variaciones con lo antes visto y/o se repite de temporadas anteriores; lo que aparece con mayor frecuencia (puede ser un recurso, un concepto, materiales, etc.).

Los registros de la observación son fotográficos y se recolectan tanto en ferias, como en las calles y las vidrieras.

\section{Análisis e interpretación}

Como producto del relevamiento in situ, se obtienen más de 10.000 imágenes propias, tanto del contexto urbano, de las ferias y sus foros de tendencias, de la forma de vestir de la gente en la calle, de las vidrieras de marcas líderes y emergentes. Este material sirve de base para el procesamiento, al que se le incorpora lo recolectado en la primera fase de la investigación.

El análisis e interpretación de esta enorme cantidad de información, se realiza a partir de la mirada y percepción del equipo de trabajo, que lo hace con ojos y mente argentinos, para el mercado nacional, ya que la mayoría de las empresas y emprendedores abastecen al mercado local (Argentina exporta menos del $2 \%$ su producción (2008) y esa exportación la realizan empresas argentinas de marcas locales, que exportan sus colecciones locales).

La interpretación se realiza en distintos niveles, como capas concéntricas, de diferente extensión temporal y profundidad metafórica. Como inicio de la secuencia, se analizan las tendencias macro sociales y las de consumo, que sirven para explicar y dar contexto a la indumentaria; se caracterizan por su intensa componente conceptual, explicativa del devenir social y tecnológico futuro esperable, con proyección a más de 3 años. Es la mirada sobre las grandes corrientes del consumo y sus principales variables. 
En relación a los conceptos, se utilizan ideas-fuerza amplias, abarcadores y fuertemente inspiracionales. Pretenden plasmar ideas e imaginarios, desafiantes, poéticos, creativos.

En un segundo nivel de análisis se estructura la información recogida, para cada temporada, desde las vidrieras y la gente en la calle, las pasarelas, las ferias, las paletas de colores, para que, luego de un proceso de intensa discusión, se encuentren los ejes que alinearán los contenidos de la presentación. Estos ejes sirven de ordenadores, constituyendo matrices que organizan la información y facilitan la interpretación.

La idea rectora es que este material puede ser tomado por cada empresa como fuente inspiracional, que le permita la creación de colecciones originales con alta coherencia, respondiendo a las expectativas y aspiraciones del público consumidor al que atiende.

\section{Difusión accesible}

El material procesado, en imágenes y textos, se hacen accesibles al público en general, en presentaciones abiertas, de una jornada, con la participación del equipo completo como oradores. Los participantes disponen de la información en soportes magnéticos.

Las presentaciones, coincidentes con las temporadas, se adecuan a los diferentes públicos, poniendo más énfasis en los requerimientos y necesidades de cada uno de ellos, en función de su estructura, madurez, rubro y mercado al que atienden. Es así que la audiencia incluye tanto a profesionales del diseño de empresas consolidadas, con un alto nivel de profesionalización, que recurren para la confirmación de sus propuestas; a empresarios recientes o de rubros específicos, que buscan la información más relacionada con el producto (textiles, recursos, colores); a responsables de talleres que tienen marcas aún no consolidadas; a docentes de las carreras de diseño; a diseñadores independientes. Corresponde una mención especial, al análisis e interpretación de tendencias en calzado, como una separata especializada, de continuidad con el auspicio de los empresarios del sector.

\section{El proceso de la investigación, con foco local Mapa de diseño argentino - "Por la calle"}

Con una década de experiencia recorriendo circuitos líderes en textiles e indumentaria, el Observatorio ha desarrollado una propuesta de análisis e interpretación del fenómeno de la indumentaria con identidad argentina, de forma sistemática desde 2007, con el lema desafiante de "Argentina como generadora de tendencias".

La socióloga Susana Saulquin, quien participó activamente en la creación de la forma de trabajo y los primeros resultados del Observatorio, reflexionaba así, en 2006:

Desde el año 2001 -crisis nacional y cambio global, con los atentados del 11-S mediante-, puede decirse que tuvo lugar el inicio de un cambio en las relaciones entre las personas y la percepción de los objetos que las rodeaban. A mediados de la década de 1990, en todo el mundo, a medida que se profundizaba la globalización económica y cultural, comenzó a manifestarse una fuerte 
necesidad de gestionar y encontrar la identidad, individual y colectiva. En el plano individual, esta búsqueda se vio facilitada por el encuentro con el diseño de autor, potenciado a partir de la crisis del 2001; en el plano nacional, surgía la necesidad de tener una marca país con una identidad definida. Si bien, en este contexto, las grandes organizaciones industriales con ramificaciones planetarias y enormes presupuestos se afianzaron cada vez más, también se asistió a un renacer conjunto de pequeños emprendimientos locales, en respuesta al diseño globalizado e impersonal, pensado para mercados masivos (Saulquin, 2006).

Se utiliza la misma metodología de investigación, basada en la observación, con el mismo equipo profesional que recorre las ciudades del mundo, a la que se suma las entrevistas en profundidad a los diseñadores y la elaboración de sus perfiles creativos (fuentes inspiracionales, imaginarios, materiales habituales, elementos conceptuales que los identifican, colecciones, formación profesional).

En este caso, el objetivo del Observatorio, va más allá de informar e interpretar, haciendo hincapié en la difusión del diseño argentino, teniendo para esta finalidad como aliado estratégico y operativo a la Fundación Pro Tejer, entidad referente del toda la cadena agroindustrial textil e indumentaria del país.

\section{Investigación de campo en el país}

El relevamiento inicial de los circuitos de diseño en Argentina, se basó en información disponible inicial sobre zonas/barrios, donde hubiera una concentración de locales comerciales con propuestas de diseño independiente.

El trabajo de campo consiste en recorrer las ciudades o barrios, calle por calle, identificando los locales comerciales de indumentaria con propuestas que se alejan de las tendencias, que el equipo del Observatorio sabe detectar con facilidad.

En todos los casos, el equipo viaja al lugar en un reconocimiento inicial, para identificar contextos, propuestas de diseñadores y locales comerciales y se observa y analiza la originalidad de las propuestas en las prendas/colecciones.

Los primeros circuitos identificados, de diferente magnitud por la cantidad de diseñadores y/o locales, fueron los de Buenos Aires (San Telmo, Palermo, Botánico, Recoleta), Rosario y Córdoba. La investigación se extendió hasta completar 17 provincias identificando los núcleos urbanos con diseñadores independientes, en Mendoza, Tucumán, Salta, Jujuy, Corrientes, Posadas, Neuquén, Resistencia, Mar del Plata, La Plata, Neuquén, San Isidro, La Rioja, Santa Rosa y se ha ido re-actualizando desde 2008.

\section{Difusión accesible: El mapa de diseño argentino - "Por la calle"}

El mapa de diseño argentino, textil e indumentaria, surge como resultado del relevamiento del país, identificando y ubicando a los diseñadores con propuestas que se distancian de las tendencias, poniendo énfasis en los recorridos temáticos y geográficos. 
A fines del 2010 el mapa incluía a más de 200 diseñadores independientes, con producciones de indumentaria con identidad argentina y con presencia comercial sostenida.

El Observatorio asumió como desafío, la difusión de estos diseñadores independientes entendiendo que, como lo señala la ingeniera Patricia Marino (2010), directora del INTI textiles, "el diseño de indumentaria de autor en Argentina es hoy una realidad que cobra cada vez más importancia, no sólo desde el punto de vista económico sino también como fenómeno cultural en tanto expresión de identidad nacional."

Los formatos básicos de difusión del Mapa de diseño se basan en la existencia de una página web en la que se mantienen actualizados los perfiles de las empresas y diseñadores independientes y los eventos denominados Por la calle (http://www.xlacalle.com/).

El nombre del evento refleja de forma contundente, que el fenómeno del diseño independiente no es un hecho aislado o puntual, sino que está instalado en las ciudades, de forma natural... está Por la calle

$\mathrm{Y}$ ¿qué es Por la calle?

...Es una propuesta de recorridos por circuitos urbanos donde el diseño textil y de indumentaria está presente, para descubrir aprendiendo a mirar las claves de la identidad del diseño en la Argentina.

Decimos aprendiendo a mirar, teniendo en mente sumarle a las percepciones de cada persona que participe, una guía para comprender e interpretar, las tendencias, que se están generando en la Argentina.

Por la Calle circuitos de diseño, se desarrollará en jornadas, una para cada circuito, con una propuesta que conjuga lo didáctico con lo lúdico, en la que se podrán seguir diferentes recorridos, visitando los locales en donde se encuentra la producción de los diseñadores.

Estos recorridos tendrán la orientación temática de los diseños como hilo conductor (xlacalle, 2010).

A modo didáctico, los recorridos se hacen temáticos: el de aquellos diseñadores que trabajan interviniendo las texturas, fundamentalmente con estampas, incluyendo las estampas con materiales no tradicionales (recorrido textura); otros que trabajan con las formas, con los cortes, con las morfologías, con nuevas propuestas de ensambles en las prendas (recorrido forma) y un último grupo cuyo eje son los ensambles trabajando con materiales textiles y no textiles, en combinaciones creativas, no convencionales (recorrido ensamble).

El día del Por la calle, la zona/el barrio se viste de fiesta, con globos, los locales son señalizados y se distribuyen folletos con el mapa del barrio/ciudad, con los recorridos dibujados. Estos recorridos son autoguiados, para que el público los pueda recorrer más allá de la jornada festiva. Los locales suelen estar atendidos por los propios diseñadores, quienes comparten con el público sus formas de crear y sus imaginarios. En las tiendas hay propuestas participativas, desde la confección de prendas conjunta (tejido colectivo), estampados en la vereda, intervención de vidrieras con artistas plásticos, vidrieras vivientes, música en vivo, etc. Los formatos de integración entre el público y el diseño son inagotables y sorprendentes.

La convocatoria a la prensa es intensa, la producción de notas, tanto gráficas como televisivas, dan cuenta del nivel de novedad que representa para la sociedad, estas nuevas propuestas de 
diseño, originales y con identidad propia.

La idea premisa de identificar el diseño independiente en todo el país, con una mirada federal fue uno de los principios rectores del trabajo conjunto entre el INTI y la Fundación.

En 2007 se desarrollaron las primeras ediciones del Por la calle en Palermo y Rosario, con notable éxito de comunicación al público en general, cumpliendo los objetivos de la propuesta de difusión. En 2008, además de los anteriores se sumaron Córdoba, Recoleta y San Telmo. Para el 2009, se consolidaron todos los circuitos anteriores y se agregaron los de Mendoza y Tucumán, que recibió a diseñadores de Salta y Jujuy. En 2010 se realizaron los 7 circuitos, acompañados de muestras de mayor duración, en entidades culturales locales, donde el diseño local quedó exhibido en contextos artísticos locales.

En síntesis, un mapa de más de 200 diseñadores con identidad local y más de 20 ediciones de eventos de difusión del diseño argentino en indumentaria son el reflejo del talento y la creatividad argentinos.

\section{Referencias Bibliográficas}

Allen, W. (2003). Citas de Woody. El cuentómetro de Mort Cinder. Disponible en: http://www. cuentometro.com.ar/439.htm

Citas y proverbios. Disponible en: http://www.citasyprobervios.com/index.html

Echeverría, R. (2005). Ontología del lenguaje. Buenos Aires: Granica.

Informe. (2009). Claves, Información competitiva. Buenos Aires.

Marino, P. (2010). Diseño de indumentaria de autor en Argentina. Diagnóstico productivo e impacto económico basado en la Encuesta Nacional de Diseño de Indumentaria de Autor 2010. (1 ra edición). Buenos Aires: Ediciones INTI.

Pérez Zelaschi, M., Azcárate, D. y Berlingueres, R, (1999). Tesis de Maestría en Comercialización. Madrid: ESEM.

Saulquin, S. (setiembre 2007). Diario La Nación.

xlacalle (2010). Disponible en: http://www.xlacalle.com.ar

Summary: Observatory of trends of INTI Textile: its reason of being, social and productive context, forms of work of the multidisciplinary group, methodologic contributions, the results of more than one decade of interpretation of clothing phenomenon, national as well as international, making information accessible to designers and entrepreneurs from around the country.

Key words: author fashion design - diffusion - fashion trends - observation.

Resumo: Observatório de tendências do INTI Textiles: sua razão de ser, o contexto social e produtivo, as maneiras de trabalho do grupo multidisciplinário, os aportes metodológicos, os resultados de mais de uma década de interpretação dos fenômenos do vestir, tanto nacionais como internacionais, fazendo accesível a informação a desenhadores, emprendedores e empresários de tudo o país.

Palavras chave: design de autor - difusão - observação - tendências em indumentária. 